\title{
The Intensive and Extensive Margins of Real Wage Adjustment
}

\author{
Mary C. Daly \\ Federal Reserve Bank of San Francisco \\ IZA \\ Bart Hobijn \\ Arizona State University \\ March 2016 \\ Working Paper 2016-04
}

http://www.frbsf.org/economic-research/publications/working-papers/wp2016-04.pdf

\section{Suggested citation:}

Daly, Mary C., Bart Hobijn. 2016. “The Intensive and Extensive Margins of Real Wage Adjustment.” Federal Reserve Bank of San Francisco Working Paper 2016-04. http://www.frbsf.org/economic-research/publications/working-papers/wp2016-04.pdf

The views in this paper are solely the responsibility of the authors and should not be interpreted as reflecting the views of the Federal Reserve Bank of San Francisco or the Board of Governors of the Federal Reserve System. 


\title{
The Intensive and Extensive Margins of Real Wage Adjustment*
}

\author{
Mary C. Daly \\ Bart Hobijn \\ Federal Reserve Bank of San Francisco, IZA \\ Arizona State University
}

March 31, 2016

\begin{abstract}
Using 35 years of data from the Current Population Survey we decompose fluctuations in real median weekly earnings growth into the part driven by movements in the intensive margin-wage growth of individuals continuously full-time employed-and movements in the extensive margin-wage differences of those moving into and out of full-time employment. The relative importance of these two margins varies significantly over the business cycle. When labor markets are tight, continuously full-time employed workers drive wage growth. During labor market downturns, the procyclicality of the intensive margin is largely offset by net exits out of full-time employment among workers with lower earnings. This leads aggregate real wages to be largely acyclical. Most of the extensive margin effect works through the part-time employment margin. Notably, the unemployment margin accounts for little of the variation or cyclicality of median weekly earnings growth.
\end{abstract}

JEL classification codes: E24, J3, J6.

Keywords: Business cycle, labor market dynamics, wage growth.

*This paper is largely based on Daly et al. (2011). We are grateful to Alessandro Barbarino, Marianne Bitler, Michael Elsby, Henry Hyatt, Thomas Lemieux, Chris Nekarda, Ayşegül Şahin, Gary Solon, Eric Swanson, and seminar participants at the Board of Governors of the Federal Reserve System, the Kansas City, New York, St. Louis, and San Francisco Federal Reserve Banks, the NBER Labor Studies group, the Riksbank, OECD, and Tinbergen Institute for useful suggestions and comments. The views expressed in this paper are those of the authors and do not necessarily reflect the position of the Federal Reserve Bank of San Francisco or the Federal Reserve System. 


\section{Introduction}

The dynamics of real wage growth are a perennial puzzle in macroeconomics. Aggregate real wages exhibit less variability over time than standard macroeconomic models predict and observed movements appear only modestly related to business cycle fluctuations. ${ }^{1}$ Both of these patterns are evident in Figure 1 which plots growth in real median weekly earnings and the unemployment rate. As the figure shows, aggregate real wage growth, measured as median weekly earnings, varies less than the unemployment rate, a standard measure of business cycle movements. ${ }^{2}$ Moreover, and in contrast to most models, there is no consistent pattern of comovement between wage growth and the unemployment rate. ${ }^{3}$ Over the course of our sample, aggregate wage growth has looked procyclical, countercyclical, and acyclical. ${ }^{4}$

Previous research attempting to reconcile the data with the theory have focused on two wedges: (1) changes in workforce composition, namely countercyclical increases in the average marginal product of workers, and (2) departures from neoclassical wage setting practices, including models of wage bargaining and wage rigidity. The results confirm that both factors play a role. ${ }^{5}$ That said, neither can fully account for the range of variation highlighted in

\footnotetext{
${ }^{1}$ Several authors have concluded that wages are modestly tied to business cycle conditions: for example, Lucas (1977); Mankiw (1989); and Christiano \& Eichenbaum (1992). See Abraham \& Haltiwanger (1995) for a survey of empirical studies of real-wage growth over the business cycle.

${ }^{2}$ The limited variability of aggregate real wage growth fails the predictions of a variety of macro models including real business cycle models (Hansen, 1985) and models of frictional unemployment (Shimer, 2005). The flipside of this is that unemployment, employment, and hours tend to move more than these models predict, suggesting that most of the adjustments in the labor market come through quantities rather than prices.

${ }^{3}$ While most models expect wages to exhibit some cyclicality, the direction depends on the model. For example, Kydland \& Prescott (1982), Robert J. Barro (1984), Rotemberg \& Woodford (1992), and Bartelsman et al. (1994) all posit procyclical real wages while a countercyclical relationship is predicted by Keynesian with sticky wages. See Swanson (2007) for a brief review of these issues.

${ }^{4}$ In contrast to the movements of aggregate real wage growth, real wage fluctuations of individuals have been found to be consistently procyclical, rising as the unemployment rate falls and falling as the unemployment rate rises. Moreover, in keeping with standard macro theory, the size of the response is non-trivial. For example, several authors including Bils (1985), Gary Solon (1994), and Devereux (2001) find that a one percent increase in the unemployment rate reduces real-wage growth of individuals by about 1.3 percentage points. This pattern holds across decades and for various subpopulations of the labor market.

${ }^{5}$ For example, previous studies have shown that employment losses during economic downturns disproportionately occur workers with lower than average wages (Hines et al., 2001). This upskilling implies less variation in aggregate real wages than would be implied by models where workers are homogeneous and wages adjust uniformly (Altonji \& Devereux, 2000). Research has shown that controlling for composition bias, wages are highly procyclical (Perry, 1972), (Bils, 1985), and (Gary Solon, 1994) In general, models of wage bargaining have been used to explain why aggregate wages adjust less than employment or hours and nominal rigidities
} 
Figure 1. Moreover, these factors have proven difficult to capture in standard macro models, making them of limited use in addressing some of the key puzzles related to labor market adjustment over the business cycle. This is because the typical margins of wage adjustment in macroeconomic models relate to worker flows into and out of employment and to a lesser extent from job-to-job. These margins are not easily linked to observations on compositional shifts in worker quality or to rigidities created by wage setting practices.

Our paper fills this gap by examining the dynamics of real wage adjustment as they relate to intensive and extensive adjustments in the labor market. Specifically, we decompose the fluctuations in aggregate real median weekly earnings displayed in Figure 1 into the wage growth of continuously full-time employed workers -the intensive margin- and the wage differences of those moving into and out of full-time employment -the extensive margin. Using this decomposition we document how the contributions of these two margins vary over the business cycle. We also net out the effects of intensive and extensive margin adjustments over time and relate them to the observed variance and cyclicality of aggregate real wage growth. Our results provide useful guidance to macro modelers interested in tracking the differential responses of labor market prices (wages) and quantities (unemployment).

The key results are as follows. Both the intensive and extensive margins affect real wage growth, but their relative contributions vary over the business cycle. The intensive margin is procyclical and accounts for most of the variance of real wage growth, mainly due to wage changes among job switchers. The extensive margin is countercyclical and, in business cycle downturns, offsets more than half of the procyclicality of the intensive margin. During recessions, much of the extensive margin adjustment comes from flows between full-time employment and part-time/self-employment and between full-time and not-in-the-labor-force. This was especially important during the Great Recession. Somewhat surprisingly given its central placement in macroeconomic models of wage fluctuations, the unemployment margin is relatively less important for the variance and cyclicality of real wage growth.

have been cited as a reason for the limited cyclical responsiveness of wages (Card \& Hyslop, 1997; Lebow et al., 2003; Dickens et al., 2007; Barattieri et al., 2014; Daly \& Hobijn, 2014). See Pissarides (2009) and Kudlyak (2010) for two useful overviews. 
The remainder of the paper is structured as follows. In Section 2 we describe the Current Population Survey (CPS) data and discuss its key advantages. We then provide a narrative example of how the intensive and extensive margins affect median real wage growth in Section 3. In Section 4 we formalize this intuition and introduce a decomposition method that allows us to decompose the change in median wages into the contribution from: (1) the wage growth of continuously full-time employed workers and (2) the relative wage levels of workers entering and exiting full-time employment. In Section 5 we present the results of our decomposition of real median weekly earnings growth in the U.S. from 1980 through 2015. We conclude with Section 6.

\section{Data and Measurement Issues}

We use data from the CPS which has the advantage of being a long-standing, nationally representative, publicly available data source on earnings and labor market status. The CPS also is one of the key sources of information on aggregate U.S. wage growth. ${ }^{6}$ The most commonly quoted aggregate measure of wages derived from the CPS, and the one we focus on in our analysis, is median usual weekly earnings (MWE) of full-time wage and salary workers. ${ }^{7}$ MWE is published at a quarterly frequency. Usual weekly earnings are defined as "...earnings before taxes and other deductions and include any overtime pay, commissions, or tips usually received (at the main job in the case of multiple jobholders)." 8

\footnotetext{
${ }^{6}$ Previous research on the drivers of aggregate wage dynamics relied on smaller panel surveys which provide detailed data on individuals. For example, Bils (1985) uses the National Longitudinal Survey of Youth (NLS/Y). Gary Solon (1994), Devereux (2001), and Hagedorn \& Manovskii (2013) use the Panel Study of Income Dynamics (PSID). Gertler \& Trigari (2009), Barattieri et al. (2014) use data from the Survey of Income and Program Participation (SIPP). Card \& Hyslop (1997), like we do here, use data from the CPS.

${ }^{7}$ The focus on full-time wage earners still means that MWE is affected by fluctuations in overtime pay, as well as a trend in the average work week for full-time workers (See Perry, 1972, for a discussion of these issues).

${ }^{8}$ The CPS survey questions related to usual weekly earnings have evolved over time: Prior to 1994, respondents were asked how much they usually earned per week. Since January 1994, respondents have been asked to identify the easiest way for them to report earnings (hourly, weekly, biweekly, twice monthly, monthly, annually, other) and how much they usually earn in the reported time period. Earnings reported on a basis other than weekly are converted to a weekly equivalent. The term usual is as perceived by the respondent. If the respondent asks for a definition of usual, interviewers are instructed to define the term as more than half the weeks worked during the past 4 or 5 months (Bureau of Labor Statistics, 2011).
} 
To show how the CPS data on aggregate real wage growth compares with alternative aggregate wage measures, especially those used in other empirical studies, Figure 2 plots average hourly earnings (AHE) of production and non-supervisory workers in the private sector, compensation per hour $(\mathrm{CPH})$ in the nonfarm business sector, and the Employment Cost Index (ECI) along with MWE from the CPS from 1980 through $2011 .{ }^{9}$ All measures of nominal wages are deflated by the Personal Consumption Expenditures Price Index (PCEPI) so that the figure plots growth in real wages.

As the figure shows, all of these measures are highly correlated and exhibit similar cyclical patterns. The correlation of real wage growth measured by MWE with the other three measures is 0.6 or higher. Importantly for our work is that the MWE series captures the coincident movements of the different compensation growth measures very well. Visual inspection shows that MWE is rarely an outlier across the series in terms of fluctuations in growth. ${ }^{10}$

Importantly for our study, the CPS also provides the individual micro data underlying MWE, including information on earnings levels and labor market status. ${ }^{11}$ These micro data can be used cross-sectionally or, as we do, to construct short panels of individual respondents. To understand the type of information contained in each of these short panels it is useful to review the CPS survey structure. The CPS is a dwelling-based survey in which households are included for 16 months. Over this period, individual household members are interviewed monthly for the first four months, not interviewed for the next eight months, and then interviewed monthly again for the remaining four months before being retired from the sample. ${ }^{12}$

Table 1 provides an illustration of this structure. The regular monthly surveys collect very basic information about labor market status. Earnings information along with other details of

\footnotetext{
${ }^{9}$ For example, Gertler \& Trigari (2009) focus on AHE for the empirical analysis in their paper while Galí (2011) focuses on CPH for his estimate of the New-Keynesian Wage Phillips Curve. Lebow et al. (2003) analyze the National Compensation Survey data on which the ECI is based.

${ }^{10}$ The exception to this statement is 1994, when MWE rose much more rapidly than the other series. This coincides with the CPS redesign and the way the survey was changed to determine whether someone is a part-time or full-time employee.

${ }^{11}$ Of the four measures of real wage growth in Figure 2, MWE, which is based on the CPS, is the only one for which underlying individual level data is available that covers both the level of earnings of workers as well as their labor market status.

${ }^{12}$ Because the CPS is a dwelling-based survey, individuals who change residences are dropped from the sample.
} 
jobs are collected twice during a household survey tenure, once in survey month 4 and again in survey month $16 .{ }^{13}$ Earnings and job information are collected only for individuals who are employed at the time of the interview. Following other researchers, we rely most heavily on the information collected in survey months 4 and 16 and use the additional information collected in other survey months to refine our labor market status measures as described below. To match individuals across surveys we follow Madrian \& Lefgren (1999) and Nekarda (2009). ${ }^{14}$

Since we are interested in disentangling the intensive and extensive margins of wage growth, we construct a series of short panels based on individuals who we observe in both months 4 and 16. We then calculate an alternative MWE growth series using this sequence. This alternative MWE growth series, which we term "Matched MWE Growth" is what we decompose. Though our Matched MWE Growth measure does not exactly match the published statistic, the two are highly correlated, with a correlation of $0.79 .{ }^{15}$

To be able to link wage growth to different labor market states, we next classify individuals based on their reported labor market status. This allows us to divide individuals in our Matched MWE Growth series into five mutually exclusive groups. These are listed in Table 2. As the table shows, we first divide individuals into two groups: $(i)$ those who are continuously full-time employed and have a reported wage in both survey month 4 and survey month 16 , and (ii) those who move into or out of full-time employment and have a reported wage in either survey month 4 or survey month 16 . We label these two groups the intensive and extensive margin, respectively. This nomenclature reflects how the intensive margin of wage

\footnotetext{
${ }^{13}$ Survey months 4 and 16 are commonly referred to as the outgoing rotation groups since they are individuals temporarily moving off the sample frame or permanently retiring from the survey. The matched samples of these outgoing rotation groups are known as the MORG files.

${ }^{14}$ For more details about how we construct and match the data see Daly et al. (2011). One concern about using the CPS to track individuals over time is that the sample may not be representative of the population. Since the CPS is a dwelling based survey, when individuals change residences they are dropped from the sample and the new occupants of the unit are interviewed. While this does not alter the cross-sectional representativeness of the CPS, it can potentially interfere with representativeness of the individual-based short panels, especially if moving is related to the variables being analyzed. However, work by Nekarda (2009) and Kim (2009) that carefully corrects for this type of sample attrition finds that the biases introduced are empirically modest. Thus, we use the raw CPS matched data as our baseline for analysis.

${ }^{15}$ Due to the scrambling by the Census Bureau of identifiers that we use to match individuals across months, we are unable to perform this matching for two sub-periods of our sample, namely October 1985 through September 1986 and September 1995 through August 1996.
} 
growth captures the intensity with which continuously full-time employed workers get paid while the extensive margin captures the effect on aggregate wages of entry and exit into fulltime employment.

To enable us to further track the drivers of real wage adjustment, we further divide these workers as follows. Within the intensive margin we distinguish between: (1) Same job (S), fulltime employed in the same job in both periods, and (2) Job changers $(C)$, full-time employed in a different job from one period to the next. ${ }^{16}$ The extensive margin is split up by transitions to or from full-time employment and: (3) part-time/self-employment $(P),(4)$ unemployment $(U)$, and (5) not in the labor force $(N)$.

Although most of these states can be directly observed in the survey data, the CPS provides no specific information on whether full-time employed earners have stayed at the same job or changed jobs over the sample. Following previous research, we impute the fraction of fulltime workers who stay in the same job versus change jobs using reported information on industry, occupation and whether or not the individual works for the same employer in both periods (Fallick \& Fleischman, 2004; Nagypál, 2008). Our measure identifies as a job changers individuals who change employers and individuals who change jobs but not employers.

\section{Labor Market Flows and Wage Growth}

To preview how intensive and extensive labor market adjustments can affect median wage growth Table 3 reports the average shares (1980-2015) of wage earners who occupy each of the five states at the beginning of the period (survey month 4) and at the end of the period (survey month 16) as well as the fraction of these workers who earned below median earnings in the period. The first thing to note is that the vast majority (89 percent) of wage earners are continuously full-time employed over a 12 month period. About 41 percent of these workers stayed in the same job over the period while about 48 percent changed jobs. Of the remaining

\footnotetext{
${ }^{16}$ Making this distinction is important given the different cyclical patterns of wage growth among job stayers and job changers (Bils, 1985; Devereux, 2001; Hagedorn \& Manovskii, 2013; Haefke et al., 2013).
} 
wage earners, 2.6 percent of those full-time employed at the beginning of the year end up unemployed at the end of it and about 2.6 percent of those full-time employed at the end of the year were unemployed at the beginning. In contrast, flows into and out of full-time employment from part-time/self-employed and not in the labor force are substantially larger. The fact that so many flows occur along these margins suggests that they could play a bigger role in real wage adjustments than normally considered.

The second thing to note is that the distribution of earnings among those flowing into, or out of, full-time employment lies well to the left of that for the continuously full-time employed. About half of those continuously full-time employed earn wages below the median; job stayers have slightly higher earnings than job changers. In contrast, about two-thirds (63.9 percent) of full-time workers who exit to unemployment were earning below median wages. An even larger fraction, 72.5 percent, of those making the reverse transition, from unemployment to full-time employment, make less than median earnings. This means that in general when unemployment rises, it disproportionately pulls out workers making below median earnings. Holding the wages of other workers constant, this serves to increase in the aggregate median wage. The part-time/self-employed and not in the labor force margins contribute in a similar way. Most of their flows into and out of full-time employment occur below the median. Thus, when exits from full-time employment to part-time employment/self-employment and not-inthe-labor-force increase, the aggregate median wage tends to rise.

These results highlight the potential for both intensive and extensive margins in the labor market to matter for aggregate real wage growth. We now turn to a more formal method of quantifying these effects and tracking their relative importance over the business cycle.

\section{Formal Decomposition of Median Real Wage Growth}

Our goal is to formally track the contributions of the intensive and extensive margins to fluctuations in median real earnings growth over the business cycle. Developing a method to tracking the median and its drivers, rather than the more straightforward mean, is important 
for several reasons. ${ }^{17}$ First, the growth rate (log change) of the median is what is published quarterly by the Bureau of Labor Statistics. Second, in surveys of individual earnings, such as the CPS, the aggregate mean can be affected by missing or implausible values at the lower end and top coding at the upper end of the earnings distribution. Finally, the methodology used to decompose the median can be applied to decompose any percentile of the wage growth distribution, allowing for a much richer understanding of how intensive and extensive margin adjustments affect fluctuations in wage inequality.

The problem is that percentiles, such as the median, are nonlinear functions of the underlying conditional percentiles. As such there is no way to directly decompose the movements in the unconditional median into the contributions of the changes in the medians of different subgroups. To get around this researchers have proposed two different approaches. Both of these approaches involve relating the change in the median to shifts in distribution functions over time.

The first approach, developed by DiNardo et al. (1996), decomposes the change in the distribution function by calculating a series of counterfactual distribution functions and implied medians based on iteratively altering the drivers of interest. This method is especially useful for evaluating large changes in distributions over long periods of time. The main drawback of this method is that it is not additive. Consequently, the decomposition can lead to over- or under-explaining the total change in the median.

As discussed in Fortin et al. (2011), a second possible approach is to linearize the change in the distribution function with respect to the log-level of the wage. By construction this results in an additive decomposition of the change in the median. Our decomposition is an application of this second approach. Because it involves a linear approximation, this method is useful for analyzing small changes over relatively short periods of time. The annual changes in the distribution of log-wage levels that we analyze exactly fit this use.

\footnotetext{
${ }^{17}$ If we were interested in mean real wage growth this would be simple. We could apply a standard shift-share decomposition of the type used by Juhn \& Potter (2006) to investigate changes in labor force participation or Bartelsman et al. (2004) to investigate average labor productivity growth.
} 


\section{1 "Shift-share" analysis of change in log real earnings distribution}

Our method performs a shift-share-type analysis of the change in the cumulative distribution function. To see this consider Figure 3. The figure plots two log-earnings distribution functions, $F(W)$ and $G(W)$. These are the earnings distribution functions at the beginning and end of the period, respectively. The medians associated with these two distribution functions are given by $w$ and $w^{\prime}$.

To illustrate the relationship between changes in the median and changes in the underlying distribution function we assume, without loss of generality, that there is positive growth in the percentile over the period and that $w^{\prime}>w$. These percentiles satisfy

$$
1 / 2=F(w)=G\left(w^{\prime}\right) .
$$

The decomposition proceeds as follows. First, we decompose $F\left(w^{\prime}\right)-F(w)$ and $G\left(w^{\prime}\right)-$ $G(w)$ into contributions by the intensive and extensive margins we examine. We then apply the mean value theorem to translate these contributions, measured along the vertical axis in Figure 3, into changes in earnings along the horizontal axis, i.e. $w^{\prime}-w$. This yields the decomposition of the change in the median of log earnings.

A standard shift-share analysis is based on the fact that the unconditional mean is the marginal-density-weighted sum of conditional means. For our analysis we exploit that, similarly, the unconditional CDF is the marginal-density-weighted average of the conditional CDFs. In particular, we condition on the labor market states, $l$, listed in Table 2.

We denote the fraction of full-time employed wage and salary workers in each of these states at the beginning of the period by $\phi(l)$ and their wage distribution conditional on their labor market state by $F(W \mid l)$. This allows us to write

$$
F(W)=\sum_{l} \phi(l) F(W \mid l) .
$$

A similar decomposition can be applied to $G(W)$. 
This observation allows us to apply a shift-share decomposition to the change in the distribution functions at the median at the beginning of the period, i.e. at $w$. This yields

$$
\begin{aligned}
F(w)-G(w) & =\sum_{l \in\{S, C\}} \phi(l)[F(w \mid l)-G(w \mid l)] \\
& +\sum_{l \in\{P, U, N\}} \phi(l)[F(w \mid l)-1 / 2]-\sum_{l \in\{P, U, N\}} \gamma(l)[G(w \mid l)-1 / 2] \\
& -\sum_{l \in\{S, C\}}(\gamma(l)-\phi(l))[G(w \mid l)-1 / 2] .
\end{aligned}
$$

Here $\gamma(l)$ and $G(W \mid l)$ are definined in a similar way to $\phi(l)$ and $F(W \mid l)$. Each of the three lines in the above equation capture a different reason for the shift in the distribution function.

For the job stayers, $S$, and the job changers, $C$, the first line measures the difference between the fraction of each of these groups that is below the median at the beginning of the period and the fraction that is below the median at the end of the period. That is, for each of the two categories of continuously full-time employed the first line gives the fraction of them that moved across the median. This is equivalent to the shift-part of a conventional shift-share analysis. Because this line captures the effect on the distribution of wage changes for the continuously full-time employed, we denote this as the intensive margin effect on the distributional shift.

The two terms in the second line of equation (3) reflect the effect of exit out of and entry into full-time employment on the wage distribution respectively. For each group, the first term measures the fraction of those that exit from below the median. Exit from below the median, i.e. $F(w \mid l)>1 / 2$, shifts the wage distribution rightward, increases $F(w)-G(w)$, and thus puts upward pressure on the median. Hence the plus sign in front of this first term. The second term measures the fraction that enters below the median. Such entry tends to shift the wage distribution leftward and pull down the median. This is why this term is preceded by a minus sign. Because the terms in the second line of equation (3) quantify the part of the distributional shift that is due to entry and exit, we include this in the extensive margin effect on the wage distribution dynamics. 
As for the third line of equation (3), if net entry is zero, such that

$$
\sum_{l \in\{P, U, N\}} \phi(l)=\sum_{l \in\{P, U, N\}} \gamma(l),
$$

then, by definition, $\gamma(S)=\phi(S)$ and $\gamma(C)=\phi(C)$, and the third line is zero.

It is not necessarily zero when there is net entry into or exit out of full-time employment. This line captures the effect of the net entry share on the wage distribution. For example, consider the case in which net entry is negative and there is no full replacement of outflows out of full-time employment, $\gamma(l)>\phi(l)$. If exit exceeds entry for groups that generally earn less than the median, such that, $G(w \mid l)>1 / 2$, then this shifts the wage distribution rightwards and pushes up the median wage. This is the distributional version of a conventional share effect. Because this share effect is only non-zero in case there is net entry or exit, we include it in the extensive margin of the dynamics of the wage distribution.

In terms of Figure 3, equation (3) decomposes $F(w)-G(w)$, which is the downward arrow at the median at the beginning of the period, $w$. Similarly, one can apply the same decomposition at the median at the end of the period, $w^{\prime}$. As is most commonly done in shiftshare analyses, we do not take a stance on which one of these decompositions is preferred. Instead, we decompose the sum of the both of them. That is, we use

$$
\begin{gathered}
{[F(w)-G(w)]+\left[F\left(w^{\prime}\right)-G\left(w^{\prime}\right)\right]} \\
=\sum_{l \in\{S, C\}}\left\{\phi(l)[F(w \mid l)-G(w \mid l)]+\gamma(l)\left[F\left(w^{\prime} \mid l\right)-G\left(w^{\prime} \mid l\right)\right]\right\} \\
+\sum_{l \in\{P, U, N\}} \phi(l)\left\{[F(w \mid l)-1 / 2]+\left[F\left(w^{\prime} \mid l\right)-1 / 2\right]\right\} \\
-\sum_{l \in\{P, U, N\}} \gamma(l)\left\{[G(w \mid l)-1 / 2]+\left[G\left(w^{\prime} \mid l\right)-1 / 2\right]\right\} \\
-\sum_{l \in\{S, C\}}(\gamma(l)-\phi(l))\left\{\left[F\left(w^{\prime} \mid l\right)-1 / 2\right]+[G(w \mid l)-1 / 2]\right\} .
\end{gathered}
$$

Though the terms in this equation are longer than in equation (3), the main intuition of what makes up the intensive and extensive margins of the shift in the earnings distribution remains the same. Using this method we are able to divide the change in the wage distribution function 
in every period into the parts driven by the intensive and extensive margins of interest.

\subsection{Translating changes in CDFs into changes in the median}

The shift-share-type decomposition of the shift in the distribution function introduced above divides changes along the vertical axis in Figure 3 into parts due to the intensive and extensive margins. However, our aim is not to decompose the shift in the earnings distribution function but, instead, to decompose changes in the median. These changes in the median are movements along the horizontal axis in Figure 3. The final step then is to translate the change in the CDFs into changes in the median.

This translation can be done by applying the Mean Value Theorem. To apply the Mean Value Theorem, we first use the fact that $w$ and $w^{\prime}$ satisfy equation (1) to write

$$
[F(w)-G(w)]+\left[F\left(w^{\prime}\right)-G\left(w^{\prime}\right)\right]=\left[G\left(w^{\prime}\right)-G(w)\right]+\left[F\left(w^{\prime}\right)-F(w)\right] .
$$

If $F(W)$ and $G(W)$ are continuously differentiable with associated density functions $f(W)$ and $g(W)$ then, according to the Mean Value Theorem, there exists $w^{*} \in\left[w, w^{\prime}\right]$ such that

$$
\left[G\left(w^{\prime}\right)-G(w)\right]+\left[F\left(w^{\prime}\right)-F(w)\right]=q^{*} \times\left(w^{\prime}-w\right), \text { where } q^{*}=\left[f\left(w^{*}\right)+g\left(w^{*}\right)\right]
$$

The constant, $q^{*}$, that translates changes in the distribution function into change in the median is the sum of the earnings density at the beginning and end of period evaluated in $w^{*}$. Since these densities, by definition, reflect the fraction of the population, i.e. the y-axis variable in Figure 3, per unit of the wage, i.e. the $\mathrm{x}$-axis variable in Figure $3, q^{*}$ is a well-defined and interpretable translation factor.

Another way of interpreting this translation factor is to consider a linearization of the change in the distribution function. For illustrative purposes we consider this linearization 
with $w$ as the expansion point. Such a log-linearization yields that

$$
\left[G\left(w^{\prime}\right)-G(w)\right]+\left[F\left(w^{\prime}\right)-F(w)\right] \approx q \times\left(w^{\prime}-w\right), \text { where } q=[f(w)+g(w)] .
$$

The error of this first Taylor Approximation tends to be small when we evaluate relatively small changes in the median. If the changes in the median are small then

$$
q=f(w)+g(w) \approx q^{*}=f\left(w^{*}\right)+g\left(w^{*}\right) \approx q^{\prime} \equiv f\left(w^{\prime}\right)+g\left(w^{\prime}\right)
$$

Thus, for the relatively small changes in the median that we study in this paper, the translation factor, $q^{*}$, can be interpreted as sum of the earnings densities at the beginning and end of the period evaluated at the median.

The most important insight from the application of the Mean Value Theorem in equation (7) is that, because $q^{*}$ is the same for all subgroups, the shares of the contributions of the intensive and extensive margins in the change in the distribution functions are the same as those in the change in the median. We use this result for our decomposition. In particular, we use equation (5) to divide the change in the distribution function into parts due to the different subgroups from Table 2. We then use the translation constant to rescale these contributions such that they reflect changes in the median log wage rather than the earnings distribution function.

\section{Results}

In the remainder of the paper we present the results of our decomposition. We begin by reviewing how the contributions of the intensive and extensive margins to aggregate median wage growth vary over time. We then discuss the key findings in the context of the standard assumptions embedded in many macro models. We conclude with a discussion of the average contributions of the intensive and extensive margin and how these average contributions vary 
over the business cycle.

\subsection{Time-series results}

Figure 4 plots the time series of the contributions of the intensive and extensive margins to median real wage growth. The first thing to note is that the intensive margin drives wage growth. The intensive margin effect is the dominant driver in all decades of our sample and was especially important during the strong labor markets of the mid 1980's and the late 1990's. The second thing to note is that the net effect of entry and exit-the extensive margin-is to depress wage growth, as workers with higher wage levels are replaced by entrants into fulltime employment with wages below the median. During recessions, the extensive margin becomes less negative, partially offsetting the procyclical slowdown in wage growth among the continuously full-time employed. Although the magnitude of the effect varies from recession to recession, it generally is not very large.

The exception to this general characterization is the recent Great Recession. During this period, the extensive margin contribution turned from negative to positive, something previously unseen in the data. The decline in the drag from entry and exit owed to a surge of exits from full-time employment that largely occurred from below the median. This upskilling pushed aggregate median wage growth above that of the continuously full-time employed. This effect was amplified by the near stoppage of entry into full-time employment during the period, since entrants largely earn below median wages. Combined, these two extensive margin effects elevated aggregate median wage growth higher during the recession and early stages of the recovery than it would have been otherwise.

Figure 5 further decomposes the intensive and extensive margins into the more detailed labor market states. Panel 5a of the figure shows the contributions of job stayers and job changers to the total intensive margin effect. The results reveal that those who change jobs over the year contribute more to the intensive margin than those who remain in the same job. This owes to the fact that the share full-time employed who change jobs, $C$, is larger than 
the share who stay in the same job $S$, while the earnings changes, or shifts, of $C$ and $S$ are similar.

When labor markets are tight, job changers contribute more to wage growth; the $C$ effect is amplified by an increase in the share of job changers and an increase in the fraction who move from below to above MWE. In labor market downturns, job changing and the wage returns to changing fall such that job changers contribute roughly the same to wage growth as those who stay in the same job. This means that the wage growth effect of $C$ and $S$ converge. In general, during labor market expansions the strong performance in terms of wages of those who are in $S$ and $C$ (displayed in Figure 4) is accentuated by an increase in their share. The result is that the intensive margin contributes procyclically to real wage growth.

Turning to the sub-groups details of movements in the extensive margin displayed in Panel $5 \mathrm{~b}$, all of them contribute to the countercyclicality of the extensive margin on real wage fluctuations. Though small, even the replacement components for same job and job changers move countercyclically.

Relative to standard models, the contributions to fluctuations in the extensive margin are surprising. The part-time/self employment margin contributes the most of any sub-group. The magnitude of the part-time/self employment effect relative to other margins owes to the fact that a larger fraction of flows into and out of part-time/self-employment occur from below MWE. In business cycle downturns, more workers move from full-time to part-time boosting the share of exits to this margin. At the same time there is little change in the earnings differences associated with these flows, with nearly all of it taking place below the median. Focusing in on the Great Recession highlights the impact of this part-time/self-employment margin. The incidence of involuntary part-time employment increased sharply during the Great Recession, causing the countercyclical contribution of the part-time and self-employed, $P$, to the extensive margin of real wage growth to increase substantially after 2008 .

Another surprisingly large contributor to the fluctuations in the extensive margin is notin-the-labor-force $N$. The $N$ effect is always larger or as large as the unemployment margin. During labor market expansions, a larger share of individuals enter full-time employment from 
not-in-the labor force. Since the vast majority, around 80 percent, enter at below median earnings, the larger share pulls down wage growth. In recessions, this effect is tempered by a reduction in the share of workers flowing into full-time employment from not-in-the-labor force and an increase in workers flowing out of full-time employment to not-in-the-labor force. This causes the $N$ effect to be countercyclical. In the Great Recession this countercyclical contribution was especially pronounced, even turning positive for a short period. At this point, the $N$ effect is again a drag on aggregate median wage growth, largely due to the inflow of new and returning workers who enter below the median. This effect is also being amplified by the secular retirement of the Baby Boom generation, who have higher wages than average workers who flow from full-time to not-in-the-labor force.

\subsection{Why doesn't unemployment matter more?}

Unemployment is the prevalent extensive adjustment margin considered in most macroeconomic models. However, the results in Figure 5b show that unemployment is less important than other margins, both in terms of contributions to extensive margin fluctuations and in terms of the countercylicality of the extensive margin. Here we discuss the underlying movements in shares and shifts that drive the contribution of $U$. We will refer to Table 3 which reports the average share and shifts components of unemployment, Figure $6 \mathrm{a}$ which shows the time series of the share of full-time employed exiting to and entering from unemployment, and Figure $6 \mathrm{~b}$ which shows the accompanying fraction of flows into and out of unemployment from below the median.

Consider first the average effect of $U$ on the extensive margin adjustment Table 3, row

4. As with the other extensive margin sub-groups, entrants to full-time employment from unemployment are more likely to come from below the median than are exits from full-time employment. However, the impact of this difference is attenuated by the fact that the flows into and out of unemployment are relatively small when compared to the flows into and out of part-time/self-employment and not-in-the-labor-force. Moreover, on average exits to and 
entry from unemployment are roughly equal, so that only relative wages of entrants and exiters contribute to $U$.

Of course, the average effect of $U$ varies over the business cycle. During expansions, more workers enter from unemployment than exit to unemployment, see Figure 6a. This serves to amplify the drag on aggregate wage growth coming from $U$. In recessions, the opposite occurs, more workers exit full-time employment, than enter full-time employment, from unemployment. At the same time, as Figure 6b shows, the incidence of unemployment rises in the wage distribution such that the fraction of exits coming from below the median falls. This means that the share effect (flows) and the shift effect (relative wages) are moving in opposite directions. On net, this serves to temper the impact of unemployment on wages as the share and shift effects partially offset.

\subsection{Adding it all up}

Our decomposition allows us to express the time series of 12-month log change of real MWE, $\Delta \ln \left(w_{t}\right)$, as the sum of the seven components shown in Figure 5. We index these components by $c_{i, t}$, where $i=1, \ldots, 7$, such that we can write

$$
\Delta \ln \left(w_{t}\right)=\sum_{i} c_{i, t}
$$

The fact that the individual components add up to the aggregate time series that we study allows us to assess how important they are, on average, over our sample period 1980-2015Q1, for the variance and cyclicality of real MWE growth.

To measure the contribution of each of the components to the variance of real wage growth, we apply a simple variance decomposition. The additive relationship in equation (10) allows us to write the variance of aggregate real wage growth as the sum of the covariances between each of the individual components, $c_{i, t}$, and the aggregate, $\Delta \ln \left(w_{t}\right)$. Column I of Table 4 lists the share of each of the components in the variance of real wage growth. Rows 3 through 7 of the table show that each of the composition effects only account for a small share of the variance 
of real wage fluctuations. In total, the extensive margin accounts for only 10.4 percent of the variance of real MWE growth. The other 89.6 percent is due to the intensive margin. In fact, wage changes of job changers, $C$, alone account for half of the fluctuations in real wage growth over the past three decades (row 2, column I).

As for the cyclicality of real wage growth, we measure it by the slope coefficient, $\beta$, from a simple regression of real wage growth on the level of the unemployment rate, $u_{t}$. Both real wage growth as well as the unemployment rate are measured in percentage points in this regression. The particular regression equation is

$$
\Delta \ln \left(w_{t}\right)=\alpha+\beta u_{t}+\varepsilon_{t}
$$

The coefficient is reported in the top row of column II of Table 4 and equals -0.124 and is not significant. This indicates that over the past 35 years real wage growth has only been mildly procyclical. Real wage growth has tended to be high when the unemployment rate was low and vice versa. However, this relationship has not been particularly strong, leading to the statistical insignificance of the coefficient.

By construction, the cyclicality coefficient, $\beta$, is the sum of seven component-specific cyclicality coefficients, $\beta_{i}$ for $i=1, \ldots, 7$, obtained using regressions of the form

$$
\Delta \ln \left(w_{t}\right)=\alpha_{i}+\beta_{i} u_{t}+\varepsilon_{i, t}, \text { where } i=1, \ldots, 7 \text {. }
$$

These component-specific coefficients are listed in rows 1 through 7 of column II of Table 4 . As can be seen from the table, on the one hand, each of the components of the extensive margin, except that for unemployment, is significantly countercyclical. On the other, each of the components of the intensive are significantly procyclical. Though the intensive margin is more important than the extensive margin for the cyclicality of real wage growth, half of its movements over the business cycle are undone by entry into and exits out of full-time employment. This is why the aggregate cyclicality coefficient is negative, just like that associated 
with the wage growth effect, but statistically insignifant.

\section{Conclusion}

Using data from the Current Population Survey from 1980 through 2015 we examined what drives the variance and cyclicality of the growth rate of real wages over time. To do this we employed a novel decomposition technique that allows us to divide changes in percentiles of aggregate usual weekly earnings growth into the part associated with the wage growth of continuously full-time employed workers-the intensive margin-and the part associated with relative wage levels of individuals entering and exiting full-time employment-the extensive margin.

The relative importance of these two margins varies significantly over the business cycle. When labor markets are tight, continuously full-time employed workers drive wage growth. During labor market downturns, the procyclicality of the intensive margin is largely offset by net exits out of full-time employment among workers with lower earnings. This leads aggregate real wages to be largely acyclical. Most of the extensive margin effect works through the part-time employment margin. Notably, the unemployment margin accounts for little of the variation or cyclicality of median weekly earnings growth. 


\section{References}

Abraham, Katharine G., \& Haltiwanger, John C. 1995. Real wages and the business cycle. Journal of economic literature, 33(3), 1215-1264.

Altonji, Joseph G, \& Devereux, Paul J. 2000. The extent and consequences of downward nominal wage rigidity. Chap. 15, pages 383-431 of: Research in labor economics.

Barattieri, Alessandro, Basu, Susanto, \& Gottschalk, Peter. 2014. Some evidence on the importance of sticky wages. American economic journal: Macroeconomics, 6(1), 70-101.

Bartelsman, Eric J, Caballero, Ricardo J, \& Lyons, Richard K. 1994. Customer- and SupplierDriven Externalities. American economic review, 84(4), 1075-84.

Bartelsman, Eric J., Haltiwanger, John, \& Scarpetta, Stefano. 2004 (Oct.). Microeconomic Evidence of Creative Destruction in Industrial and Developing Countries. Tinbergen Institute Discussion Papers 04-114/3. Tinbergen Institute.

Bils, Mark J. 1985. Real Wages over the Business Cycle: Evidence from Panel Data. Journal of political economy, 93(4), 666-89.

Bureau of Labor Statistics. 2011. Usual Weekly Earnings Technical Note.

Card, David, \& Hyslop, Dean. 1997. Does inflation "grease the wheels of the labor market"? Pages 71-122 of: Romer, Christina D., \& Romer, David H. (eds), Reducing inflation: Motivation and strategy. University of Chicago Press.

Christiano, Lawrence J, \& Eichenbaum, Martin. 1992. Current Real-Business-Cycle Theories and Aggregate Labor-Market Fluctuations. American economic review, 82(3), 430-50.

Daly, Mary C., \& Hobijn, Bart. 2014. Downward nominal wage rigidities bend the phillips curve. Journal of money, credit and banking, 46(S2), 51-93.

Daly, Mary C., Hobijn, Bart, \& Wiles, Theodore S. 2011. Aggregate real wages: macro fluctuations and micro drivers. Tech. rept. 
Devereux, Paul J. 2001. The cyclicality of real wages within employer-employee matches. Industrial and labor relations review, 54(4), 835-850.

Dickens, William T., Goette, Lorenz, Groshen, Erica L., Holden, Steinar, Messina, Julian, Schweitzer, Mark E., Turunen, Jarkko, \& Ward, Melanie E. 2007. How wages change: Micro evidence from the international wage flexibility project. Journal of economic perspectives, 21(2), 195-214.

DiNardo, John, Fortin, Nicole M., \& Lemieux, Thomas. 1996. Labor market institutions and the distribution of wages, 1973-1992: A semiparametric approach. Econometrica, 64(5), $1001-1044$.

Fallick, Bruce C., \& Fleischman, Charles A. 2004. Employer-to-employer flows in the U.S. labor market: the complete picture of gross worker flows. Tech. rept.

Fortin, Nicole, Lemieux, Thomas, \& Firpo, Sergio. 2011. Chapter 1 - decomposition methods in economics. Handbook of Labor Economics, vol. 4, Part A. Elsevier.

Galí, Jordi. 2011. The return of the wage phillips curve. Journal of the european economic association, 9(3), 436-461.

Gary Solon, Robert Barsky, Jonathan A. Parker. 1994. Measuring the cyclicality of real wages: How important is composition bias. The quarterly journal of economics, 109(1), 1-25.

Gertler, Mark, \& Trigari, Antonella. 2009. Unemployment Fluctuations with Staggered Nash Wage Bargaining. Journal of political economy, 117(1), 38-86.

Haefke, Christian, Sonntag, Marcus, \& van Rens, Thijs. 2013. Wage rigidity and job creation. Journal of monetary economics, 60(8), 887-899.

Hagedorn, Marcus, \& Manovskii, Iourii. 2013. Job selection and wages over the business cycle. American economic review, 103(2), 771-803. 
Hansen, Gary D. 1985. Indivisible labor and the business cycle. Journal of monetary economics, 16(3), 309-327.

Hines, James, Hoynes, Hilary, \& Krueger, Alan. 2001 (July). Another Look at Whether a Rising Tide Lifts All Boats. Working Papers 833. Princeton University, Department of Economics, Industrial Relations Section.

Juhn, Chinhui, \& Potter, Simon. 2006. Changes in labor force participation in the united states. Journal of economic perspectives, 20(3), 27-46.

Kim, Seik. 2009. Sample Attrition in the Presence of Population Attrition. Working Papers UWEC-2009-02. University of Washington, Department of Economics.

Kudlyak, Marianna. 2010. Are wages rigid over the business cycle? Economic quarterly, 179-199.

Kydland, Finn E, \& Prescott, Edward C. 1982. Time to Build and Aggregate Fluctuations. Econometrica, 50(6), 1345-70.

Lebow, David E, Saks, Raven E, \& Wilson, Beth Anne. 2003. Downward Nominal Wage Rigidity: Evidence from the Employment Cost Index. The b.e. journal of macroeconomics, 3(1), 1-30.

Lucas, Robert E. B. 1977. Hedonic wage equations and psychic wages in the returns to schooling. The american economic review, 67(4), 549-558.

Madrian, Brigitte C., \& Lefgren, Lars John. 1999 (November). A note on longitudinally matching current population survey (cps) respondents. Working Paper 247. National Bureau of Economic Research.

Mankiw, N. Gregory. 1989. Real business cycles: A new keynesian perspective. Journal of economic perspectives, $\mathbf{3}(3), 79-90$. 
Nagypál, Eva. 2008. Worker reallocation over the business cycle. mimeo. Northwestern University.

Nekarda, Christopher J. 2009. A longitudinal analysis of the current population survey: Assessing the cyclical bias of geographic mobility. mimeo. Federal Reserve Board of Governors.

Perry, George L. 1972. Real spendable weekly earnings. Brookings papers on economic activity, 1972(3), 779-787.

Pissarides, Christopher A. 2009. The unemployment volatility puzzle: Is wage stickiness the answer? Econometrica, 77(5), 1339-1369.

Robert J. Barro, Robert G. King. 1984. Time-separable preferences and intertemporalsubstitution models of business cycles. The quarterly journal of economics, 99(4), 817-839.

Rotemberg, Julio J, \& Woodford, Michael. 1992. Oligopolistic Pricing and the Effects of Aggregate Demand on Economic Activity. Journal of political economy, 100(6), 1153-1207.

Shimer, Robert. 2005. The cyclical behavior of equilibrium unemployment and vacancies. American economic review, 95(1), 25-49.

Swanson, Eric T. 2007. Real Wage Cyclicality In The Panel Study Of Income Dynamics. Scottish journal of political economy, 54(5), 617-647. 
Table 1: CPS survey design

\begin{tabular}{llccccccccc}
\hline & Survey tenure month & 1 & 2 & 3 & 4 & $\ldots$ & 13 & 14 & 15 & 16 \\
\hline 1. & Month in sample (MIS) & 1 & 2 & 3 & 4 & $\ldots$ & 5 & 6 & 7 & 8 \\
2. & Labor force status & $\checkmark$ & $\checkmark$ & $\checkmark$ & $\checkmark$ & & $\checkmark$ & $\checkmark$ & $\checkmark$ & $\checkmark$ \\
3. & Earnings data & & & & $\checkmark$ & & & & & $\checkmark$ \\
\hline
\end{tabular}




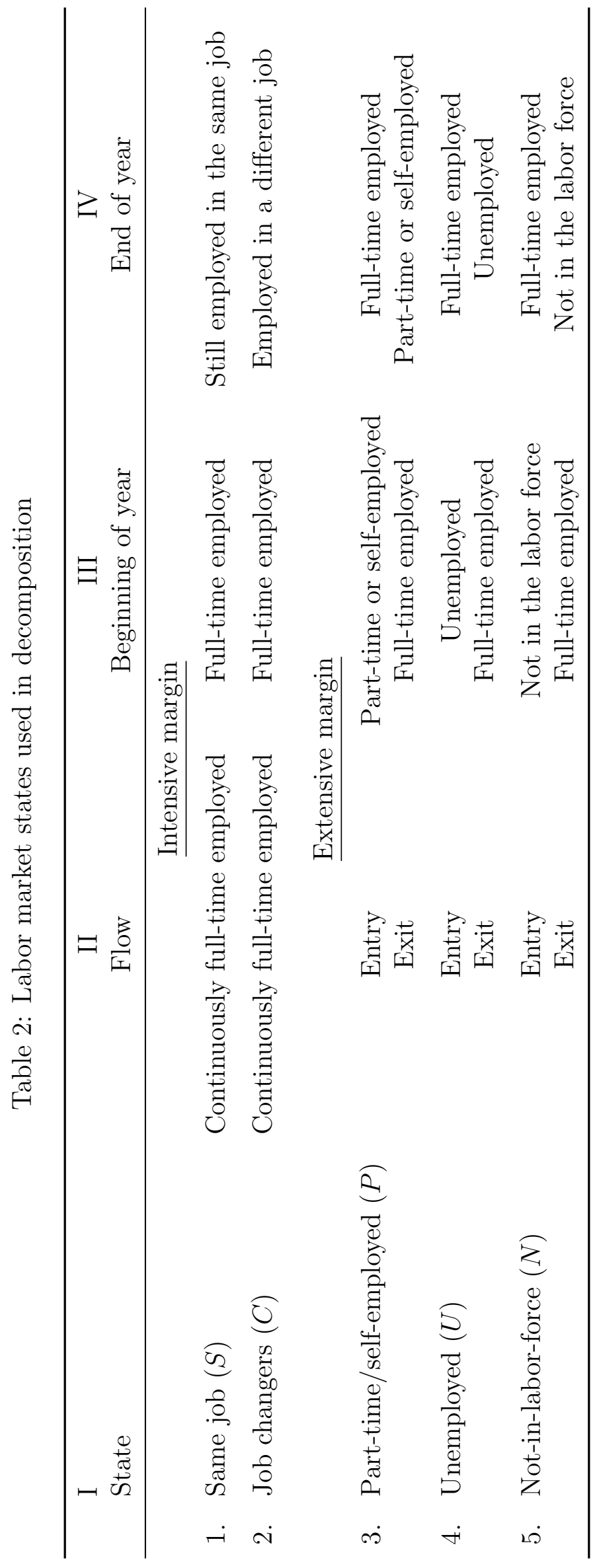

Page 26 


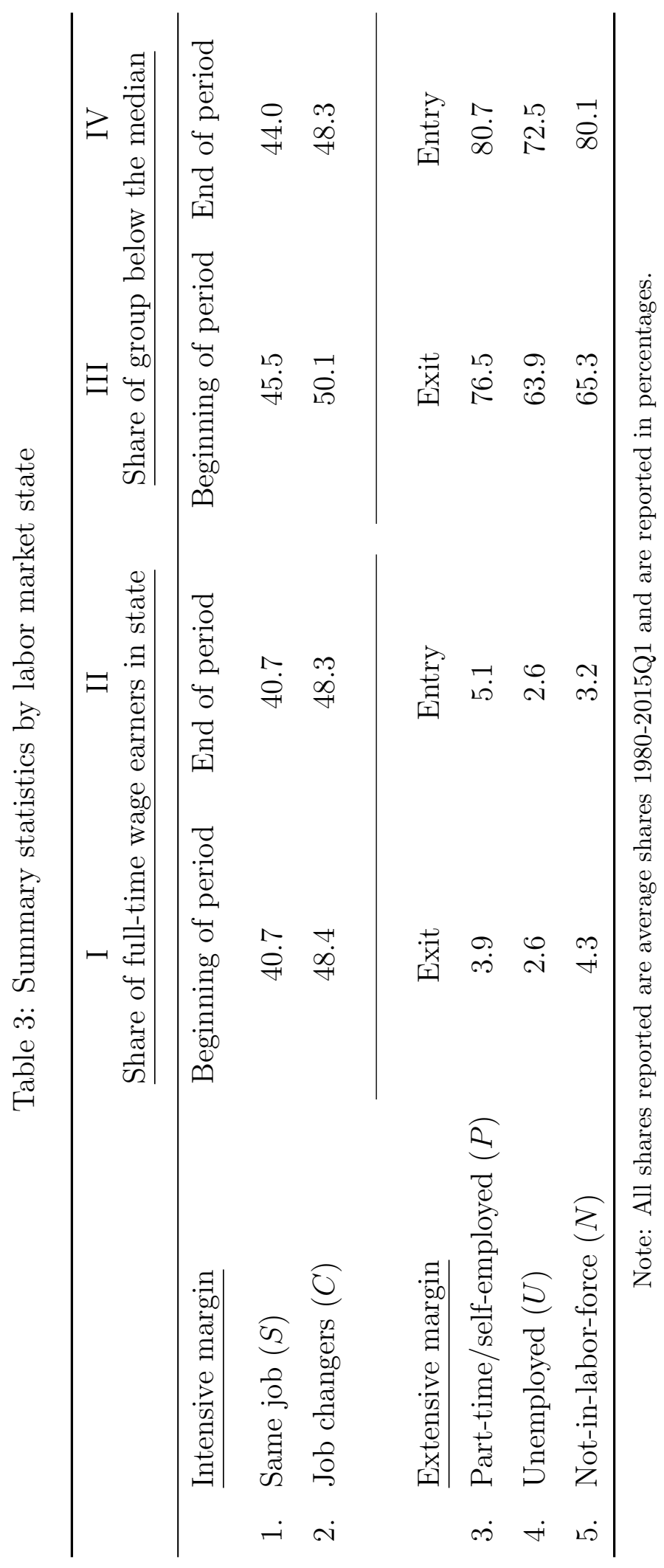

Page 27 
Table 4: Decomposition of variance and cyclicality of real MWE growth: 1980-2015Q1

\begin{tabular}{ccc}
\hline \multirow{2}{*}{ State } & I & II \\
Variance & Cyclicality \\
\hline Total & 1.9 & -0.124 \\
& & $(-1.73)$
\end{tabular}

A. Intensive margin

1. Same job $(S)$

39.6

-0.081
$(-2.37)$

2. Job changers $(C)$

$50.0 \quad-0.135$

Subtotal

\begin{tabular}{cc}
50.0 & $\begin{array}{c}-0.135 \\
(-2.96)\end{array}$ \\
\hline 89.6 & -0.216
\end{tabular}

$\underline{\text { B. Extensive margin }}$

Entry and exit components

3. $\quad$ Part-time of self-employed $(P) \quad 4.5 \quad 0.053$

4. $\quad$ Unemployed $(U)$

$3.8 \quad-0.008$

5. Not in the labor force $(N)$

$1.2 \quad 0.033$

Share components

\begin{tabular}{llcc} 
6. & Same job $(S)$ & 0.7 & 0.012 \\
7. & Job changers $(C)$ & 0.3 & 0.002 \\
& & & $0.044)$ \\
\cline { 2 - 3 } & Subtotal & & \\
\cline { 2 - 3 }
\end{tabular}

Note: Rows 1 through 7 in column I are reported in percent of the total variance reported in the top row. Totals do not add up to 100 due to rounding. Column II reports regression coefficients, $\beta$, of cyclicality regression $\Delta \ln \left(w_{t}\right)=\alpha+\beta u_{t}+\varepsilon_{t}$. Here $u_{t}$ is the unemployment rate in percentage points. The right-hand side variable is either the log change in MWE multiplied by 100 or one of its seven subcomponents we calculated as part of our decomposition. 
Figure 1: Real wage growth and the unemployment rate

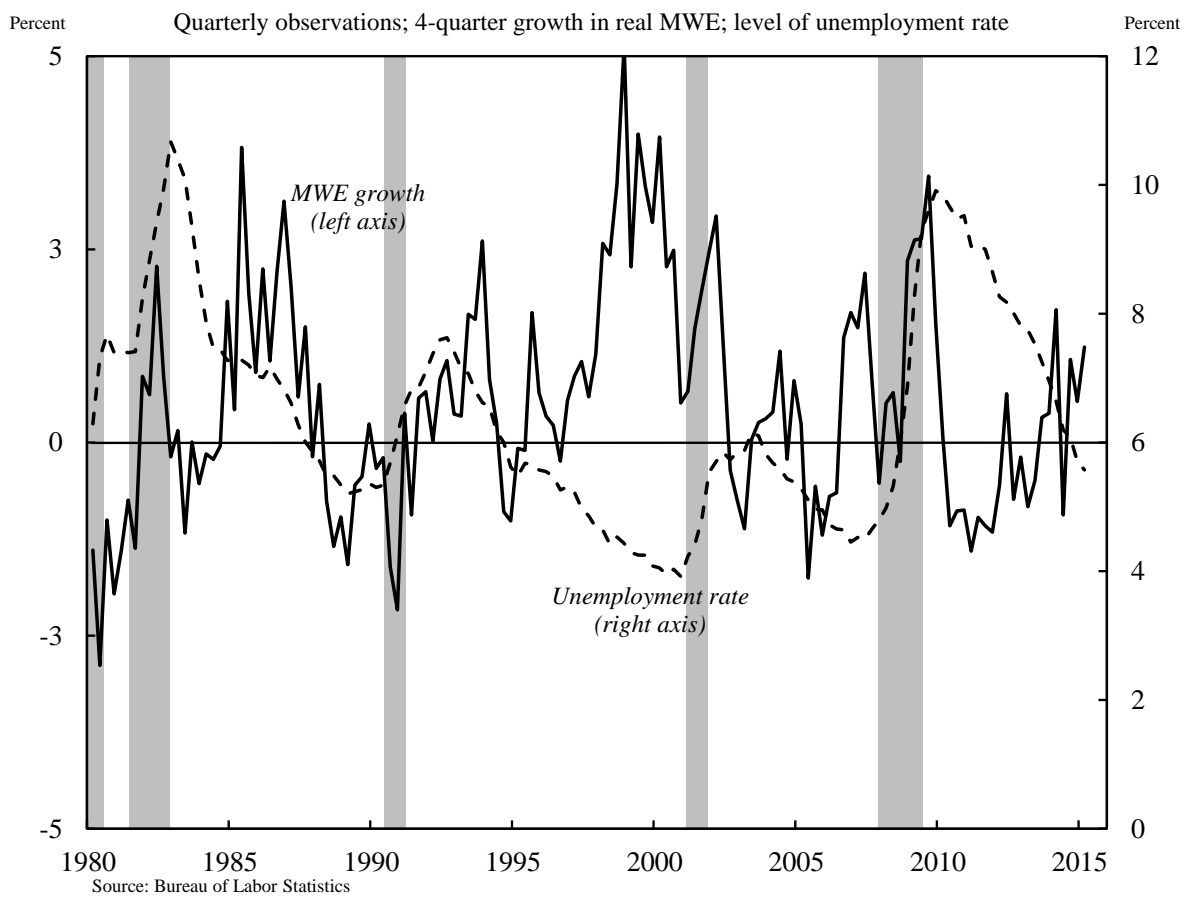

Figure 2: Four aggregate measures of real wage growth

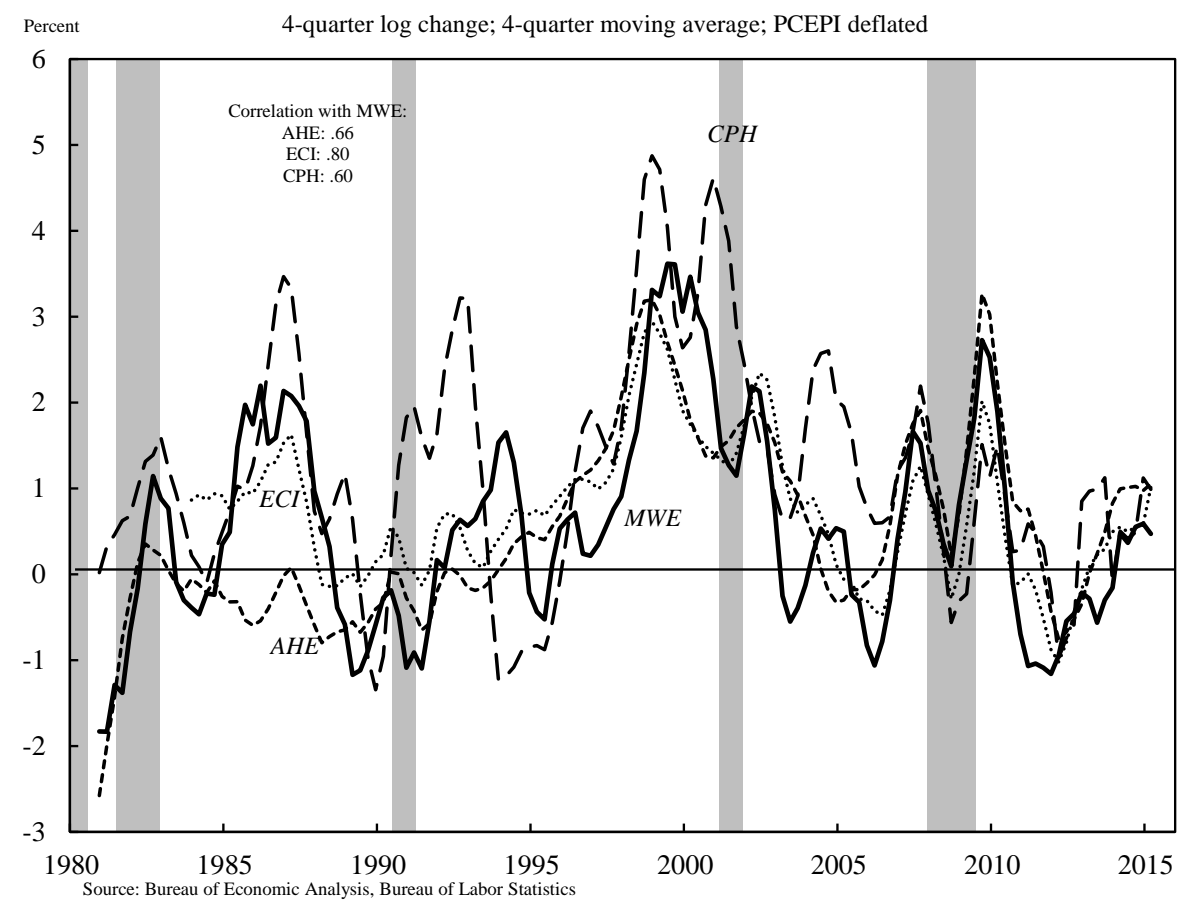


Figure 3: Changes in the earnings distribution and the log change of MWE

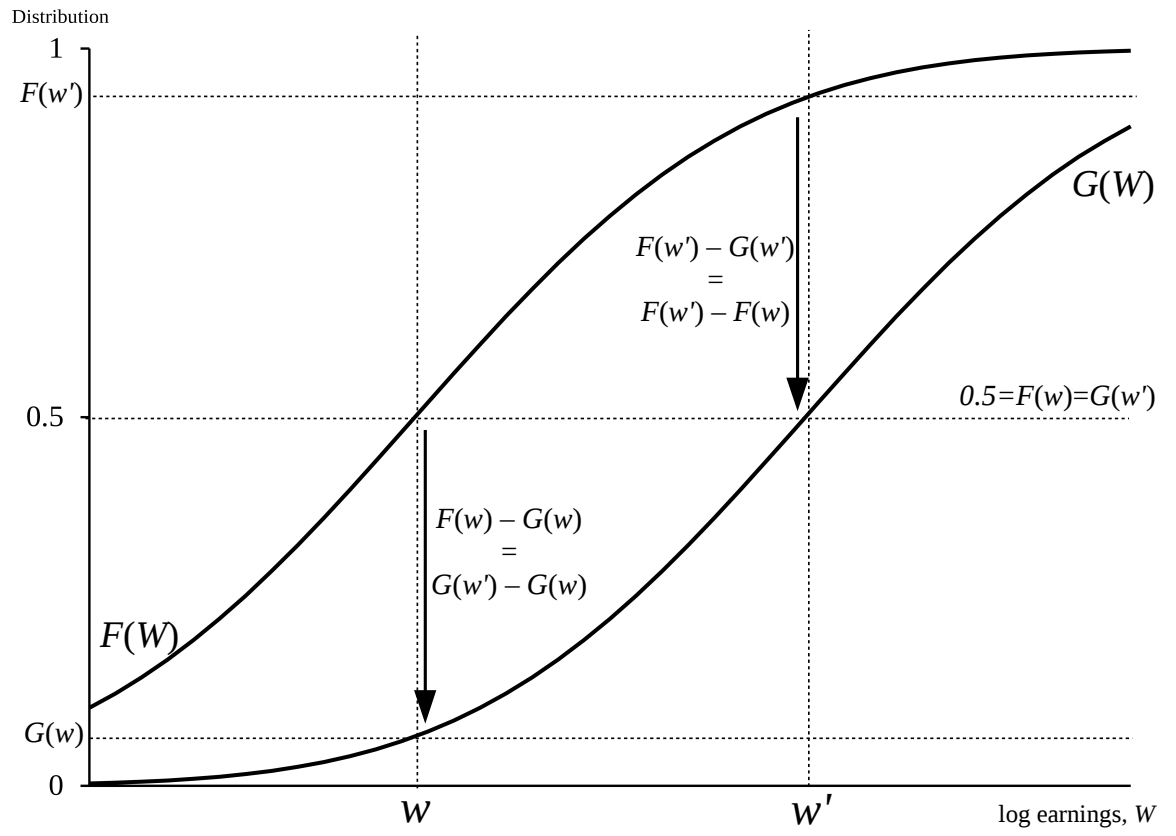

Figure 4: The intensive and extensive components of real MWE growth

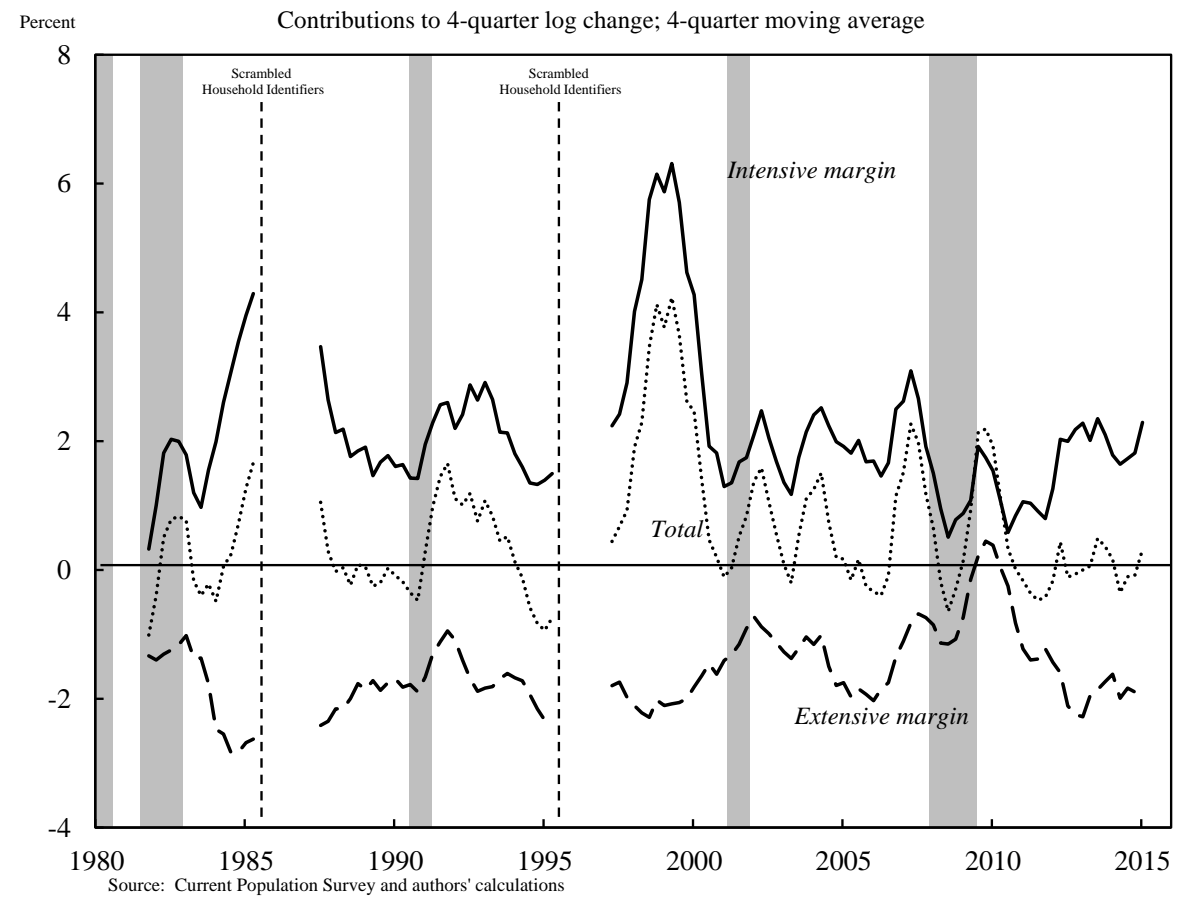


Figure 5: Decomposition of intensive and extensive margins by labor market state.

(a) Intensive margin

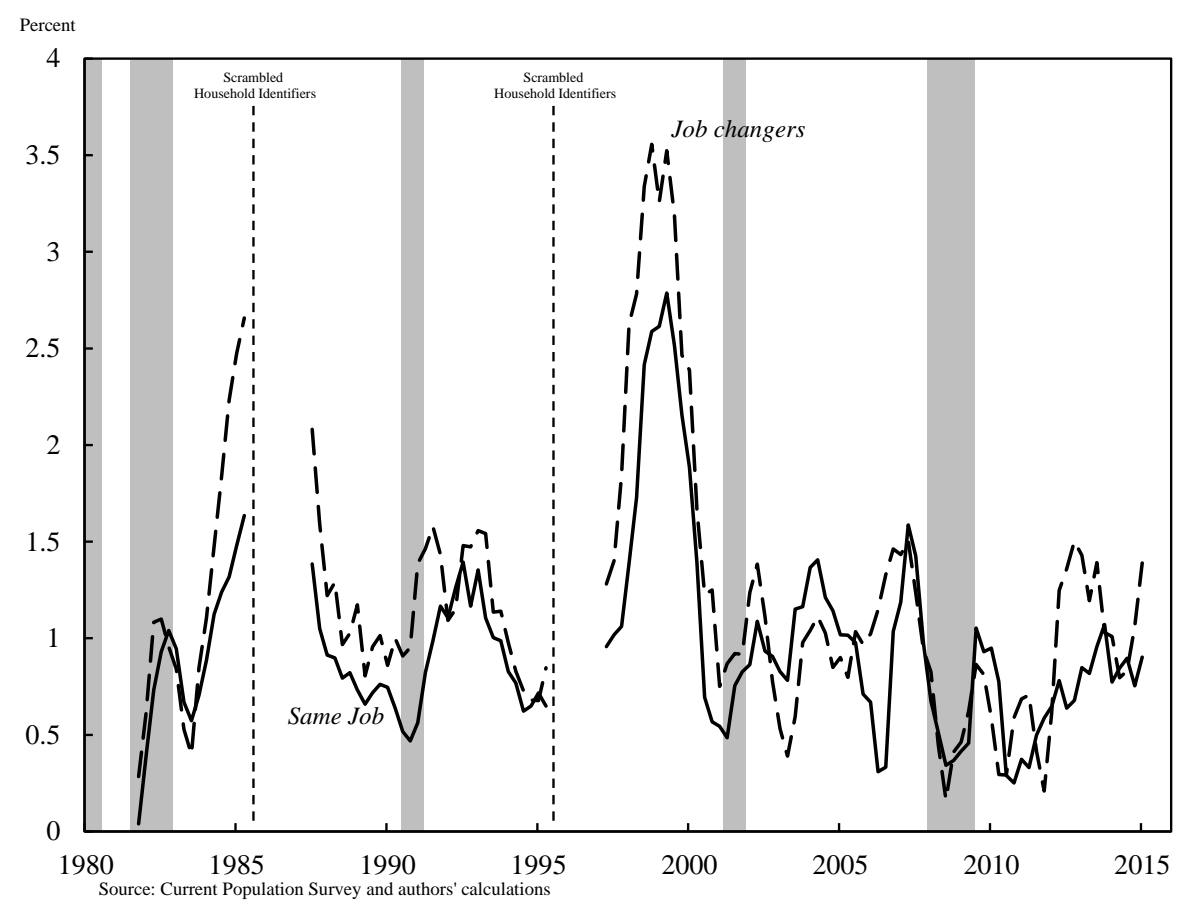

(b) Extensive margin

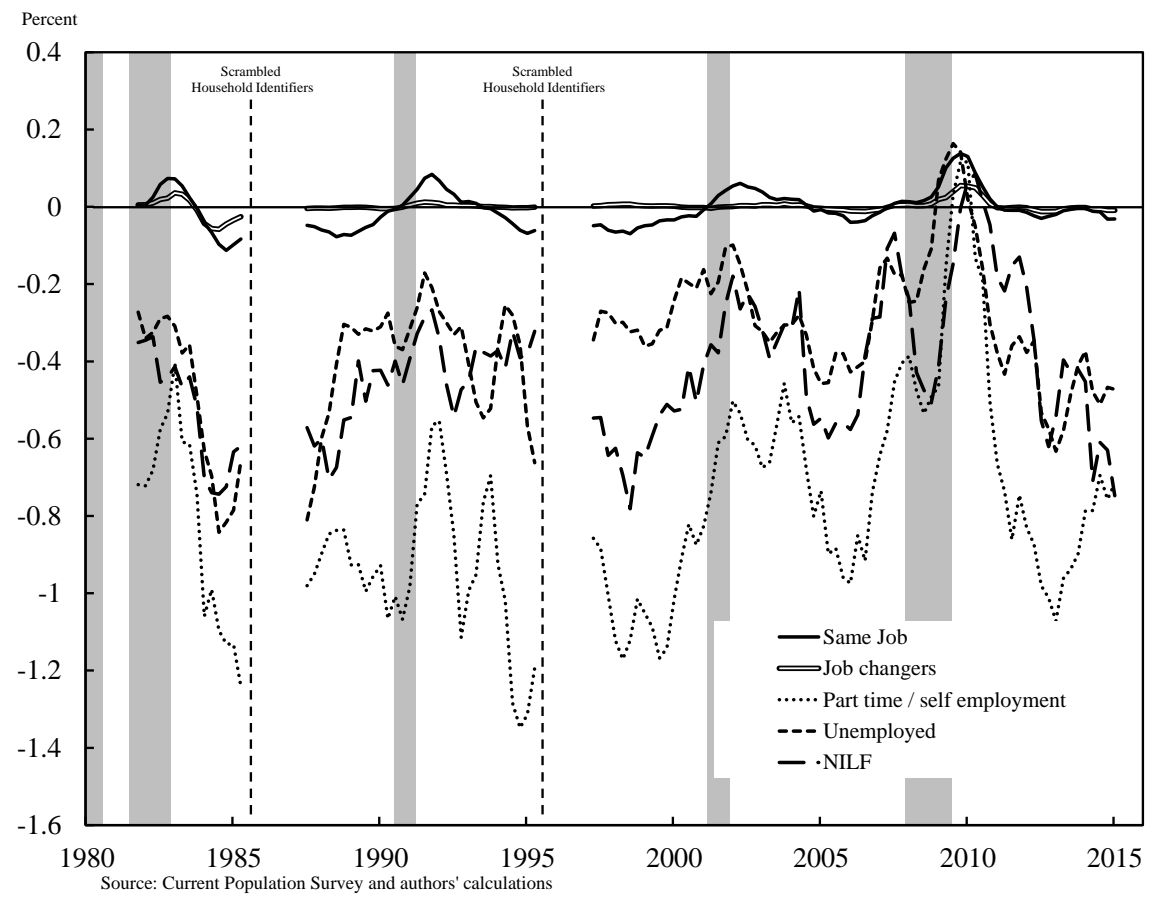

Note: All panels contain 4-quarter moving averages 
Figure 6: Shift- and share-parts of unemployment contributions to real wage adjustments

(a) Share of full-time employed exiting to and entering from unemployment

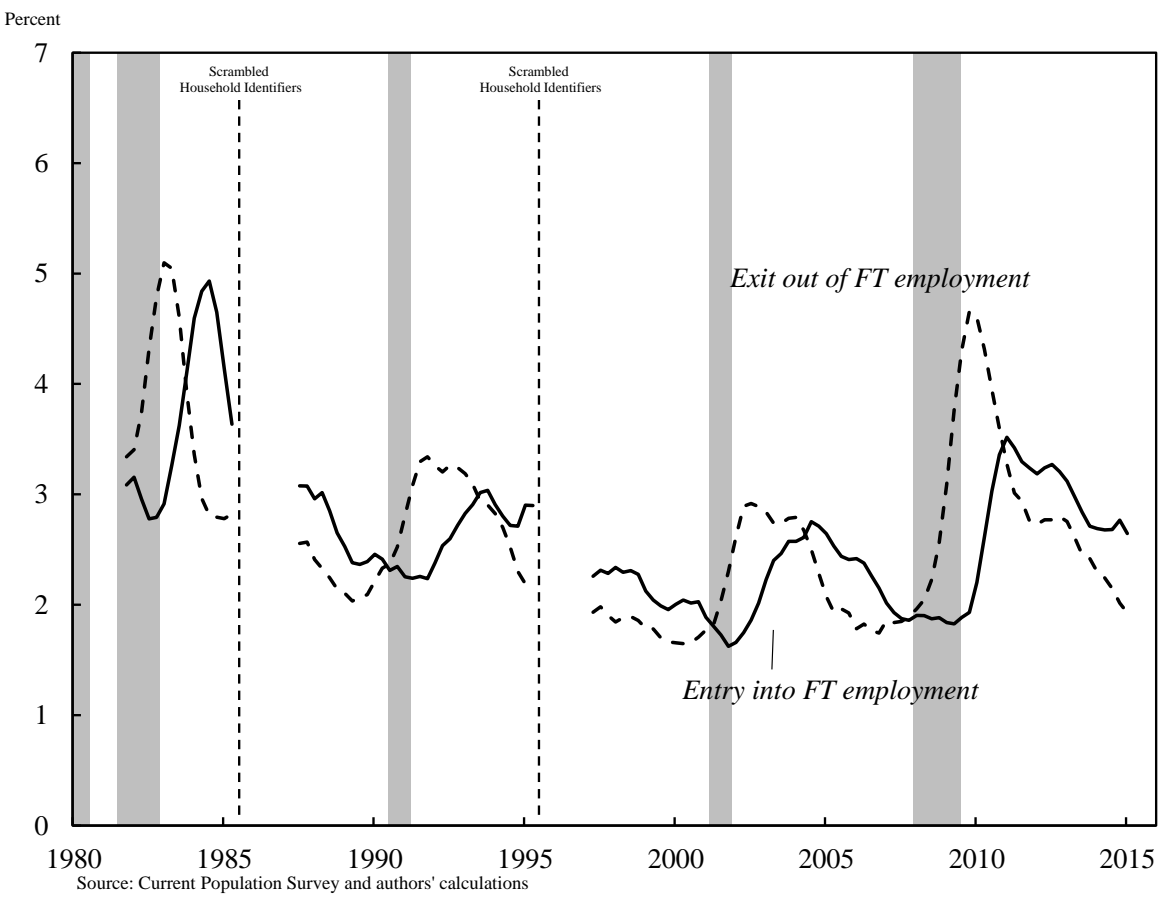

(b) Fraction of flows into and out of unemployment below MWE

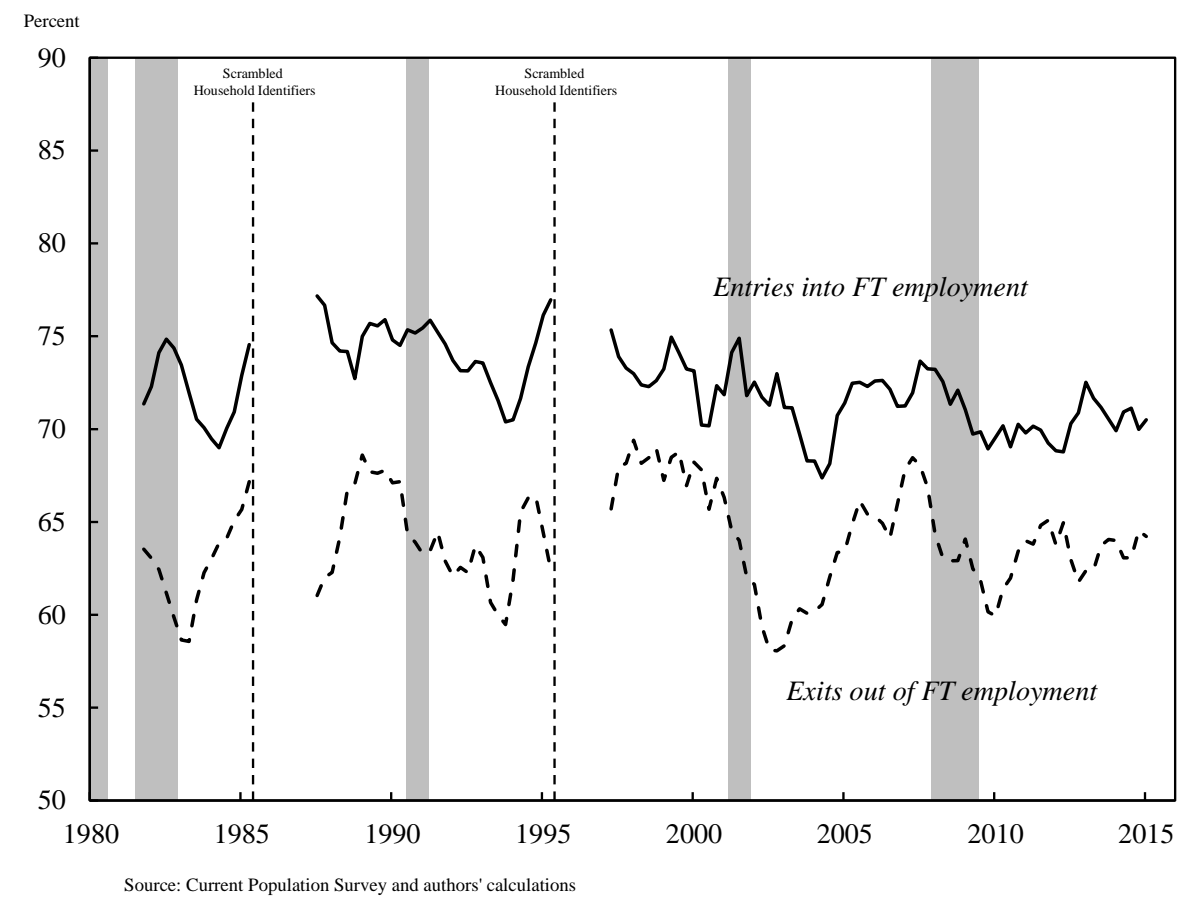

